\title{
Determination of dominance hierarchies in monkeys'
}

\author{
R. CHARLES BOELKINS 2 \\ PRIMATE LABORATORY, UNIVERSITY OF WISCONSIN
}

Two established, social groups of macaque monkeys were subjected to $24 \mathrm{hr}$. of water deprivation. Dominance hierarchies were determined by an index of elapsed time from water onset until each $S$ drank for 20 sec.

Two methods have been widely used to determine social dominance hierarchies in laboratory studies of subhuman primates. In the appetitive technique, group members are tested in all possible pairs in a competitive feeding situation (e.g., Miller \& Murphy, 1956). In the competitive avoidance technique (e.g., Hamilton, 1960) only one animal of a pair can safely avoid shock by getting on a nonshocked perch. In both methods group members typically have no social contact with each other outside the test situation, and the "group" exists only in the sense that all Ss receive the same treatment.

It is generally assumed that an animal social group is a cohesive entity which has stability and structure because of the reciprocal relations existing between all group members. But it is certainly not true that 10 animals living in separate cages (Miller \& Murphy, 1956) constitute a group in the traditional zoological sense. Thus, while a "dominance hierarchy" may be obtained by competitive pairwise testing of all possible pairs in a group, it is invalid to assume that the same order would be obtained if the animals were tested as a unit in a group social environment.

Finally, there are practical problems which are rarely mentioned. Testing $10 \mathrm{Ss}$ in all pairwise combinations means that 45 pairs, $90 \mathrm{Ss}$, must be taken to and from the test room, a time-consuming and laborious operation. Macaque monkeys appear to have insatiable appetites for raisins and peanuts. If food incentives are presented singly to a large group of animals it is unlikely that the low ranking Ss can obtain enough incentives for $E$ to determine their ranking, and other behavioral criteria must then be employed.

A water deprivation test similar to the one described here was first employed by Alexander \& Harlow (1965) as a measure of dominance in caged groups of juvenile monkeys.

Subjects

Two groups of macaque monkeys served as Ss. The Macaca speciosa group (stumptailed monkeys) consisted of two males and eight females, all sexually mature, feral adults. Following their introduction to the group pen, Ss were allowed a stabllization period of 27 weeks. The Macaca nemestrina group (pigtailed monkeys) was originally composed of 13 feral animals. Of the three males, one was fully mature (8-10 yr.) and two were subadults (3-4 yr.).
All 10 females were sexually mature, ranging in age from 4-12 yr. With the exception of the oldest male, the group had lived together for 14 weeks before the first test. The oldest male was introduced as a replacement for an extremely aggressive adult male 5 weeks before the first test.

Housing

Both groups occupied identical indoor-outdoor pens at the University of Wisconsin Regional Primate Research Center's Holding Facility. Indoor pens, enclosing $1500 \mathrm{cu}$. ft. of space over $255 \mathrm{sq}$. ft. of floor area, had steel mesh floors and ceilings and concrete walls. The outdoor pens enclosed approximately 20,000 cu. ft. of space and had 2000 sq. ft. of floor area. Large windows located on the first and second floors of the building permitted observation of the animals in either area. Continuously running water was available in both pens, and routine daily cleaning and feeding procedures were followed.

\section{Procedure}

Data were recorded on No. 1720-X paper tape by an Esterline-Angus 20-channel recorder operated from a remote keyboard. Twenty-four to $30 \mathrm{hr}$. prior to each dominance test, water to both water bowls was turned off and the bowls were dried. After at least $24 \mathrm{hr}$., deprivation was terminated when all Ss were in the indoor pen.

The duration of each drink taken by each $S$ was recorded until all Ss had accumulated more than 20 sec. of drinking time. Standing guard over the water bowl without drinking was not scored as drinking time. If two animals drank simultaneously each was scored independently. The total time which had elapsed from water onset to the point at which $20 \mathrm{sec}$. of drinking had occurred was determined for each $S$ in the group. Elapsed times were ordered from shortest to longest and each animal was assigned a rank in the hierarchy corresponding to its elapsed time rank. The order in which Ss drank was not analyzed.

Four tests were conducted on the stumptail group at intervals of 7,7 , and 14 days. Two series of tests were given to the pigtail group. The first four tests were conducted on the original group of 13 animais at intervals of 16,7 , and 7 days. Four days following removal of the alpha male and one of the low ranking females (No. 9) from the pigtail group, three more tests were conducted at seven-day intervals.

Results

The rank orders of the four dominance tests on the stumptail group yielded a coefficient of concordance (Slegel, 1956) of $.959\left(\mathrm{x}^{2}=35.54, \mathrm{df}=9, \mathrm{p}<.001\right)$. In the pigtail group the coefficient of concordance for the 
first four tests was $.870\left(X^{2}=41.76, d f=12, p<.001\right)$. Removal of the dominant male resulted in considerable instability, as was revealed by the low rank order correlation $\left(r_{\mathrm{g}}=.395, t=1.54\right.$, df $=9, p>.10$, one-tailed) between the last test before and the first test after his removal. However, a moderate level of group stability gradually reappeared as evidenced by the .762 coefficient of concordance for the second series of tests. This coefficient, $W=.762$, barely reaches $\mathrm{p}<.05\left(\mathrm{X}^{2}=22.84, \mathrm{df}=10\right)$ and represents a considerable reduction in stability when compared with the first series of tests on the group.

\section{Discussion}

Clearly, both groups of monkeys established and maintained stable dominance hierarchies. That the hierarchies were not completely rigid was evidenced by the fact that with the exception of the alpha male in each group every animal changed rank within the series of tests. The obtained reliability of the dominance orders for both groups compares favorably with Alexander \& Harlow's (1965) median test-retest coefficient of .960 . The heart of this test procedure lies in using total elapsed times to 20 sec. of drinking to determine the dominance ranks, rather than the very unreliable drinking-order.

It appears that the water deprivation dominance test has important advantages over previous techniques of dominance testing. The operationally defined rank order is obtained independently of behavioral measures involving analysis of specific types of social interactions. The fact that the amount of water which satiates thirst is very quickly ingested means that each test may be completed in very little time compared with that required for testing pairs in a competitive situation. The average total time per test for the stumptail group was $20.9 \mathrm{~min}$. and $29.4 \mathrm{~min}$. for the pigtail group.

The crucial advantage of this technique over the pairwise test methods is that it may be conducted on a seminatural group of animals within the actual group situation. It permits all natural factors which determine group structure to operate in determining the order of precedence at the water bowl. The basic technique should be applicable to any seminatural group of animals occupying an environment where $\mathbf{E}$ has control of the water supply and should validate other measures of dominance.

\section{References}

Alexander, B. K., \& Harlow, H. F. Social behavior of juvenile rhesus monkeys subjected to different rearing conditions during the first six months of life. Zool. Jb. Physiol., 1965, 71, 489-508.

Hamilton, E. C. Comparison of two methods of dominance testing in the monkey. Psychol. Rep., 1960, 6, 247-250.

Miller, R. E., \& Murphy, J. V. Social interactions of thesus monkeys: I. Food-getting dominance as a dependent variable. J. soc. Psychol., 1956, 44, 249-255.

Siegel, S. Nonparametric methods for the behavioral sciences. New York: McGraw-Hill, 1956.

\section{Notes}

1. This research was partially supported by National Institute of Mental Health grant (MH-11894) to Dr. Harry F. Harlow and NIMH fellowship (5-F1-MH-23,388) to the author.

2. The author wishes to thank Drs. H. F. Harlow, V. J. Polidora, and G. A. Mitchell for critical reading of the manuscript. 